\title{
ÉTICA E POLÍTICA: A PSICANÁLISE DIANTE DA REALIDADE, DOS IDEAIS E DAS VIOLÊNCIAS CONTEMPORÂNEOS*
}

Miriam Debieux Rosa, Taeco Toma Carignato, Sandra Letícia Berta

Miriam Debieux Rosa Professora doutora do Programa de Psicologia Clínica da USP, onde coordena o Laboratório Psicanálise e Sociedade; professora titular do Programa de Pós-graduação da Psicologia Social da PUC-SP, onde coordena o Núcleo Violência: sujeito e política.

Taeco Toma Carignato Psicanalista, doutora em Psicologia Social pela PUC-SP, faz pós-doutoramento em Psicologia Clínica no IPUSP; membro do Laboratório Psicanálise e Sociedade da USP.

Sandra Letícia Berta

Psicanalista, mestranda do Departamento de Psicologia Clínica do Ipusp; membro do Laboratório Psicanálise e Sociedade da USP; membro da EPFCL-SP
RESUMO: Procura-se demonstrar como os discursos a que são expostos os sujeitos do capitalismo avançado indicam um modo de laço que empurra o sujeito violentamente ao gozo, seja sob a forma de consumo e lucro, seja sob a forma de sofrimento. Sua estratégia é propor aos sujeitos uma realidade posta (imposta), que os abstém dos dilemas éticos, o que gera, para além do mal-estar, violências. Ressituar o sujeito e a ética como elementos indissociáveis aponta para uma política de resistência à instrumentalização social do gozo. Palavras-chave: Ética, política, violência, psicanálise, fantasia social.

ABSTRACT: Ethics and politics: psychoanalysis in face of contemporary reality, ideals and violence. The article demonstrates how the speach of post-capitalist subjects underpins a type of social bond in which they see themselves immersed in a culture that violently thrusts them toward enjoyment (jouissance) in the form of either consumption and profit or suffering. Its strategy relies on proposing the suspension of ethical dilemmas to subjects submitted to the posed (imposed) reality. Besides discontents, that results in violence. Resituating both subjects and ethics as indissoluble elements points to a resistance policy to the social instrumentalization of enjoyment.

Keywords: Ethics, politics, violence, psychoanalysis, social fantasy.

\footnotetext{
*Trabalho apresentado no seminário Experimentum mundi: arte, psicanálise e utopia, organizado pelo Programa de Pós-graduação em Psicologia Social e Institucional e pelo Programa de Pós-graduação em Artes Visuais, da Universidade Federal do Rio Grande do Sul (UFRGS), em 28 de janeiro de 2005 .
} 
tica e política estão presentes na psicanálise, especialmente quando se trata da leitura dos fenômenos socioculturais de nossa época e da interrogação da prática psicanalítica. A interface entre a política e a ética da psicanálise evidenciase nos eventos sociais e clínicos, cujos fragmentos apresentamos neste trabalho como indicadores das questões do cotidiano, os quais remetem aos discursos elucidativos de modalidades do laço social e da dimensão política do gozo, do sintoma e da construção da realidade. Os discursos a que estão expostos os sujeitos do capitalismo avançado indicam o modo de laço constituído por uma cultura que os empurra violentamente ao gozo, sob a forma de consumo, de lucro ou de sofrimento.

A astúcia desses discursos está na auto-apresentação como realidade indiscutível, equivalente à própria verdade do sujeito e do seu objeto de gozo, ambos ordenados sob a lógica do capital e do lucro. Sua estratégia é propor aos sujeitos, submetidos à realidade posta (imposta), a suspensão dos dilemas éticos. Propõe uma política que prescinde da ética, que gera, para além do mal-estar, violências. Ressituar o sujeito e a ética como elementos indissociáveis aponta para uma política de resistência à instrumentalização social do gozo.

Examinemos exemplos de discursos políticos e recortes do cotidiano para apontar a contribuição da psicanálise para a análise das modalidades de laço social propostas ao sujeito e da dimensão política do gozo.

Como primeiro exemplo, tomemos o editorial do jornal Folha de S.Paulo, de 23 de janeiro de 2005, intitulado "Escola da Ilusão Perdida”, assinado por Chico Graziano, sobre a inauguração da Escola Nacional do MST, movimento dos trabalhadores sem-terra que congrega por volta de um milhão de pessoas em torno da reforma agrária. O artigo critica o MST por suas "idéias antigas", sua "agenda do atraso”, ironizando que seus integrantes não pensam em lucro:

“É notório, mesmo que se procure dissimular, que a liderança dos sem-terra imagina derrubar o capitalismo e instalar por aqui um regime de propriedade coletiva. Parece conversa fiada, coisa de reacionário, mas não o é. Eles trabalham mesmo com as idéias antigas... a luta do MST representa hoje a agenda do atraso dentro da esquerda brasileira. Ao vislumbrar a coletivização, lembra o stalinismo. Sua estratégia das invasões de terra permite que oportunistas e bandidos se afiliem ao movimento, descaracterizando a ação política. Seu mando autoritário mantém o clientelismo nos assentamentos. Opondo-se à titulação dos novos agricultores, impede sua emancipação. Lucro, então, nem pensar.” (Grifos nossos)

A desqualificação dos seus interlocutores cresce e chega a acusações de violência. Vale lembrar que a matéria foi publicada alguns dias depois do assassinato de cinco sem-terras em Felizburgo (MG): 
“É estarrecedor. Mas retrata a pura verdade: os dirigentes do MST não são democratas. Pelo contrário, são autoritários, praticam sua política com a faca no pescoço, na base da pressão que não raro descamba para a violência. São os arautos da mudança na porrada." (Grifos nossos)

E prossegue nas acusações no artigo "Imbróglio vermelho":

"O colorido de abril esconde uma face negra, uma espécie de fascismo social-religioso. Líderes treinados, sentindo-se como enviados divinos, manipulam a miséria para invadir territórios e punir quem julgam pecadores. Fazem justiça com as próprias mãos. Exagero? Não, infelizmente."

Graziano adiciona outro argumento para destituir de valor o MST: afirma que a recente política da agricultura é um sucesso retumbante. É interessante que principie assim: "Os dados sobre a estrutura agrária mostram, sabidamente, disparidades e injustiças gritantes, herdadas do passado colonial."

Mas, descartando a importância desta afirmação, continua:

\begin{abstract}
“Entretanto... Os censos do IBGE atestam que inexiste movimento de concentração fundiária. Os estudiosos sabem disso. Da mesma forma, de latifundiária e, por conseguinte, com baixa produtividade, a agricultura recentemente se transformou em sucesso retumbante. O raciocínio é elementar: as massas metropolitanas estão abastecidas somente porque houve extraordinário aumento da produtividade agrícola. E os excedentes de exportação, responsáveis por $47 \%$ das vendas ao exterior, inexistiriam sem tecnologia agropecuária de qualidade. Quer dizer, se é verdade que o país herdou uma economia primário-exportadora ineficiente, a modernização tecnológica permitiu revolucionar a forma de produção na agricultura, integrando cadeias produtivas fantásticas."
\end{abstract}

No mesmo jornal, no mesmo dia do editorial, a Revista da Folha, em uma sessão de entretenimento composta de depoimentos e intitulada "Minha primeira vez", a jornalista Heloisa Helvécia conta sua visita a um acampamento de trabalhadores sem-terra, no vigésimo aniversário do movimento. Em “Festa no campo", ela relata a comemoração que foi atrapalhada pela chuva, mas na qual, mesmo assim, pôde observar que não encontrou "pobres-diabos manipulados por oportunistas", ou "criancinhas sendo educadas para o ódio” como, diz ela, "escreveram por aí”. E termina dizendo:

“Ideologia à parte, os sem-terra acumulam resultados em inclusão, fixação de gente no campo, ensino e geração de renda. São um milhão de pessoas vivendo em acampamentos e assentamentos, treinando jeitos mais colaborativos de viver. Tudo sob a 
lona preta que não os protege da lama nem do tiro [referência aos assassinatos citados antes]." (Revista da Folha, 2005)

O discurso de Graziano é incisivo, baseado em fatos expostos por meio de dados numéricos estrategicamente colocados para imprimir veracidade, ladeados de uma crescente adjetivação que não esconde a hostilidade. É montado com uma lógica impecável: fala da realidade, como as coisas são, como funcionam e funcionam bem. Chico Graziano defende a realidade que visa a ordem e o progresso, em oposição à ilusão vista como engano, atraso e alienação dos sem-terra. Apresenta fatos ditos concretos, supostamente indiscutíveis e refratários a meras opiniões. É um discurso dessubjetivado, obediente e reprodutor, ao modo do discurso universitário descrito por Lacan, a partir de um outro discurso, o do Mestre.

Neste sentido, contrasta com o discurso de Heloísa Helvécia que, embora, também referenciado pelos que ditam a realidade, mas precavendo-se da própria opção ideológica — “Ideologia à parte...", ressalva a jornalista — , apresenta uma outra perspectiva, subjetiva, baseada na observação da festa, sem calcar no texto ou mesmo induzir a idéia de que esgotou o tema ou encontrou sua realidade última. Também utilizando os recursos da ironia, imprime o caráter contestatório, apontando, embora não fosse esse o objetivo da matéria, o furo do discurso de Graziano. Os dois discursos permitem-nos pensar sobre as diferentes modalidades do laço social circulando no contexto contemporâneo.

Lacan chamou de discursos os laços sociais tecidos e estruturados pela linguagem. O discurso do Mestre, "quer dizer, o fato de que ele ordene, intervenha no sistema de saber..." (LACAN, 1969-70/1992, p.191), é aquele no qual o poder faz laço social entre aquele que manda e aquele que trabalha. É o laço que permite governar. Lacan baseou-se na dialética do senhor e do escravo tal como apresentada por Hegel na elucidação da constituição da consciência de si. Nesta, há uma articulação entre o desejo de um com o desejo do outro, entre a vida e a morte, entre o objeto e o gozo. Neste discurso, o saber transformador representado pelo trabalho está do lado do escravo, embora ele não saiba disso, pois o Mestre dita o que é a realidade afirmando-a como verdade.

No entanto, em Televisão (1974), diferente do que afirmara em 1969/1970, no seminário O avesso da psicanálise, Lacan apresenta o Discurso Capitalista, característico da civilização científica, como uma modalidade degradada do Discurso do Mestre, que desestabiliza o laço social dominante na sociedade contemporânea. ${ }^{1}$ No capitalismo avançado, a verdade do sujeito e de seu objeto de gozo é a

\footnotetext{
${ }^{1}$ A sociedade contemporânea tem sido apresentada por vários ângulos, dos quais destacamos a sociedade do espetáculo — segundo Débord, no final dos anos 1960 - e a cultura do narcisismo segundo Lasch, no final dos anos 1970. Aqui, não examinaremos os conceitos de Débord e Lasch, mas a incidência do discurso capitalista na produção do laço social.
} 
do atravessamento da lei do mercado na lei do desejo. A lógica do capital e lucro é apresentada como a única possível, provada pelo sucesso. Tais atravessamentos e lógica não operam sem conseqüências para o sujeito.

Zizek (1996) elucida essa questão: com o estabelecimento da sociedade burguesa, as relações de dominação e servidão foram recalcadas e parece que lidamos com seres livres, com relações isentas de fetichismo. Contudo, a verdade recalcada - a persistência das relações de dominação e servidão - emerge em um sintoma que subverte a aparência ideológica de igualdade e liberdade. Esse sintoma, ponto de emergência da verdade, diz respeito às relações sociais entre coisas, um modo de funcionamento paradigmático do sistema capitalista que incita a produção de um indivíduo, sujeito não dividido, mas fundido com seu objeto, um objeto que se pode comprar. ${ }^{2}$

O discurso capitalista esclarece uma concepção de funcionamento social em que o indivíduo se adapta a uma realidade dada. Privilegia não o sujeito, mas o indivíduo consumidor que, em sua dimensão de consumido, não encontra lugar para o seu pathos (sofrimento), para formular demandas, remetido que fica à colagem do objeto da demanda ao objeto do consumo. O desdém e a ridicularização de outras estratégias societárias que não as instituídas - estas últimas, tais como apresentadas por Graziano - expõem como é incitada a supressão da demanda e do pathos para construir 'realidades' alternativas. Conflitam com o reconhecimento de que os laços sociais/discursivos determinam o sujeito, o sentido do seu ato e dito, o seu gozo, a sua psicopatologia, o seu pathos e o transbordamento para além do sintoma, do íntimo, do privado, do individual. Nesta concepção, trata-se de pensar o modo como os sistemas, ou discursos, capturam o sujeito. E também indicar a ordem social do sintoma no capitalismo avançado (ROSA, 2004).

A sociedade regida pelo discurso capitalista, segundo Quinet (1999),

“produz sujeitos insaciáveis em sua demanda de consumo. Consumo de gadgets que essa mesma sociedade oferece como objetos do desejo. Promove assim uma nova economia libidinal. Por outro lado, ao colocar a mais-valia no lugar da causa do desejo, essa sociedade transforma cada um num explorador em potencial de seu semelhante para dele obter um lucro de um sobretrabalho não contabilizado." (QUINET, 1999, p. 4)

Ao argumento de Quinet, acrescentamos a hipótese de que o sistema gera uma nova economia libidinal que exclui o pathos e substitui a demanda de amor

\footnotetext{
${ }^{2}$ Na verdade, verificamos a convivência do discurso capitalista com o do Mestre na sociedade contemporânea. Com o fracasso do recalque, o discurso capitalista emerge como sintoma, mas não elimina o discurso do Mestre.
} 
pelo apelo ao consumo e ao lucro sobre o outro. Não basta o acesso aos bens. Visa-se a destituição do outro, germe das violências. Admite-se a existência do pathos, conforme verificamos no discurso de Graziano: "Os dados sobre a estrutura agrária mostram, sabidamente, disparidades e injustiças gritantes, herdadas do passado colonial”, mas descarta-se a sua importância, torcendo a realidade. De acordo com Graziano: “... nossas massas metropolitanas são abastecidas somente porque houve extraordinário aumento da produtividade agrícola. E os excedentes da exportação...” (grifos nossos).

Acontece que, de fato, a "extraordinária produtividade agrícola serviu mais para abastecer os mercados externos, restando às massas brasileiras apenas os excedentes da exportação (...) que inexistiriam sem a tecnologia agropecuária de qualidade" (grifos nossos). Ou seja, às “massas brasileiras”, o resto. Resto que por vezes é destruído para não prejudicar os preços (veja-se o exemplo do café na década de 1930). Hoje, garante-se que brasileiros consumam este excedente, permitindo a manutenção dos preços além de obter mais lucro. O desprezo, a destituição do sujeito "brasileiro", está no discurso de Graziano encoberto pelo elogio à "tecnologia agropecuária de qualidade". O encobrimento não descarta — pode mesmo ser considerado como responsável - o empuxo ao ódio exterminador dirigido a este sujeito destituído.

A sanha exterminadora alimenta-se no encobrimento, nas sombras do anonimato, conforme vimos nos assassinatos de dez moradores de rua no Centro de São Paulo em 2005. Para ocultar outros crimes e pelo gozo político do poder, gozo do "faço porque posso", tais crimes revelam o triunfo sobre o outro, o orgulho pela sua destruição. A audácia dos assassinos é comandada pela certeza da impunidade e por saber que revelam o papel estrutural da violência no capitalismo. Neste sistema, a história da comunidade não tem mais sentido (ROSA, 2005).

Entendemos que o desejo de destruição do outro não é motivado pelas propriedades do objeto odiado, mas aponta um real que transcende aquele para o qual se dirige a agressão. O que se quer eliminar não é só aquele que está ali, mas o real, aquilo de insuportável e ingovernável que vem do real como o impossível de ser abarcado, representado, dominado, aquilo que aponta a castração. Os moradores de rua não obedeceriam a nenhuma regra de sociabilidade, ou seja, estariam além da governabilidade. Nessa medida, mostrando-se no real, os semtetos aparecem como corpos fictícios, fora do tempo e do espaço. Não têm rosto, nome ou laço.

A abstração daquele que enuncia o discurso, como o mercado, o capital financeiro, seu caráter desencarnado e anônimo não é sem efeitos para a dimensão da lei e da castração. Segundo Rosa, 
"A eficácia do anonimato pode ser verificada no caso dos assassinatos dos moradores de rua no Centro de São Paulo. Contribuiu para superdimensionar o medo, a impotência e a servidão. O anonimato dos moradores de rua — pessoas sem nome, rosto e identidade - e o de seus assassinos - livres na obscuridade e na certeza da impunidade, a irmã da conivência — promove a corrosão das bases simbólicas da convivência. Tanto os sem-tetos como os assassinos (nas sombras) não contam e não se contam entre os outros. Esse anonimato articula-se com um outro: o dos beneficiários da concentração de renda e daqueles que anseiam por ocupar um lugar ao sol. Lugar atraente, sem dúvida, por duas razões: promove o esquecimento de que facilmente se vai para a calçada e ignora a realidade, não esperada, da perda da mercadoria que não cumpre o prometido fazer ser.” (ROSA, 2005, p.5)

Associado ao discurso capitalista que é segregador, pois não faz laço social como o discurso do Mestre - este, conforme vimos, ordena as relações, mesmo na assimetria, permitindo a governabilidade - o anonimato move uma lógica paranóica, externa ao sujeito. Junto com a abstração, faculta a convicção e a opacidade aos discursos. Mesmo que sejam emitidos por pessoas identificadas, pois estas, conforme observamos nos noticiários midiáticos, funcionam como ventríloquos das vozes poderosas (anônimas) do mercado, constrangendo a resposta do sujeito dividido.

Da mesma forma, Chico Graziano vê os trabalhadores sem-terra, não como produtos de um sistema perverso e predatório, mas como bandidos infiltrados que manteriam seu poder pela força bruta e violência, fazendo "justiça com as próprias mãos”. Ou seja, para Graziano, os sem-terra constituem o real insuportável e ingovernável e, por isso, também passíveis de extermínio. Ele anula as evidências, os nomes, os rostos e mesmo o número dos que se colocam contra seus ideais um milhão de pessoas acampadas e referenciadas por diferentes propostas de organização social, nem por isso, anacrônica ou atrasada. Equivoca-se já no título do seu editorial "Escola da ilusão perdida”. Se for ilusão, os trabalhadores sem-terra mantém-na viva pela atuação, tanto quanto Graziano mantém sua crença na "modernização tecnológica”, esta sim, revolucionária no seu ponto de vista.

Apelando aos censos do IBGE, Graziano fundamenta-se no discurso da ciência, apresentando-se como portador de um saber, quando, na verdade, é portavoz e defensor dos interesses de um setor da classe dominante, os ruralistas capitalizados. Ora, o discurso científico, em sua ânsia de objetividade, optou pela ausência do sujeito, correndo o risco de igualmente produzir ilusões e engodo, ao obturar o desejo pela certeza do eu. Se, enquanto ciência, não se precaver contra a imbricação de seus enunciados com os discursos midiáticos produzidos em torno desses mesmos enunciados, corre o risco entrar no rol do que Zizek chamou de "fantasia social". 
Safatle (2002) nos indica como Zizek, ao articular ideologia e fantasia, promove uma ampla reconfiguração do conceito de crítica da ideologia e transforma a fantasia em categoria central do político. A fantasia social leva à objetividade fantasmática, à ideologia, definida como “...uma fantasia social que estrutura a determinação do valor e da significação da realidade socialmente compartilhada. Fantasia social capaz de produzir uma “objetividade fantasmática” que tem um nome próprio: ideologia” (SAFATLE, 2002, p.188).

A fantasia é cena imaginária em que o sujeito realiza o desejo e dá direção ao gozo, sem a qual não saberia como deseja restabelecer a relação com o outro. Protege o sujeito da angústia, pois permite o investimento libidinal nos objetos que passam a ter valor e significação. Zizek está ciente do aparente erro teórico implicado nesta noção uma vez que a fantasia é essencialmente não universalizável. No texto "A ideologia entre o sonho e a fantasia: primeira tentativa de delimitar o 'totalitarismo"”, ele argumenta:

“O traço fundamental do vínculo social 'totalitário' não é justamente a perda da distância entre a fantasia que fornece os referenciais do gozo do sujeito e a lei formal-universal que regulamenta a troca social? A fantasia aí se 'socializa' de maneira imediata, a lei social coincide com uma ordem, 'Goza!', começa a funcionar como um imperativo supereu-óico. Dito de outra maneira, no totalitarismo, é realmente a fantasia que está no poder..." (ZIZEK, 1991, p.157)

Nesta afirmação, Zizek é preciso ao apontar a astúcia do totalitarismo que aproxima lei e gozo, que transforma uma fantasia na alegada realidade ou verdade última desvinculada da História da comunidade. Colada à lei formal-universal que regula a troca social, a fantasia perde seu caráter singular e ganha autonomia, expandindo-se com a promessa da possibilidade de gozo. Estende o seu manto sobre a realidade social, atendendo às premissas de um tipo de historiografia que obtura os antagonismos reais, procurando preencher todos os espaços e desmentir a negatividade do sujeito. Abarca as promessas do capitalismo e aparece no discurso capitalista. Já demonstramos que o discurso capitalista não se apresenta como laço social regulador tal como o discurso do Mestre, pois é eminentemente segregador, alheio ao laço social. Nesse sentido, como discurso capitalista, a fantasia intensifica a alienação do sujeito, fragilizando-lhe a aposta no próprio desejo, na própria verdade. Esta, sim, seria ilusão, ingenuidade, anacronismo, alienação. Cria-se, então, o paradoxo em torno do ideal tomado como ilusão.

O paradoxo em torno do ideal provém do deslocamento da função do ideal do eu para a função do supereu, instância que escraviza o sujeito, remetendo-o ao gozo ou condenando-o ao fracasso. Isto significa que existe, no capitalismo, uma passagem do ideal do eu — que regula o sujeito com marcas das insígnias 
do Outro, conduzindo-o a uma esperança de reconhecimento - para uma outra instância que seduz e escraviza o sujeito com a sua voz, ordenando-o ao gozo ou assombrando-o com o fracasso.

O fracasso é anunciado caso não se atenda à suposta realidade, como ilustra a fala de uma paciente que, preocupada com o filho adolescente, relata sua vida sob a égide do significante decepção. Ainda jovem, ela engravidou de um rapaz que mal conhecia. Hoje, serve à família "arrumadinha” dos outros, como a que gostaria de ter tido. Planos ou sonhos tem para o filho que também anda, é certo, decepcionando. Para ela mesma estes sonhos e planos fazem evocar loucura. Toca uma vida que já acabou, uma vida desiludida. A referência a um ideal de família a impossibilita de atribuir valor fálico aos acontecimentos de sua vida e a submete à idealização e à exclusão do que lhe é apresentado como critério de sucesso e felicidade.

Os termos 'ilusão’ e ‘ideal’ parecem se enredar. Freud critica as ilusões no texto O futuro de uma ilusão (1927/73), tomando as religiões como parâmetro, pois as considera determinadas por desejos infantis e como compensações à fragilidade humana, ao desamparo frente à morte. No texto Psicologia das massas e análise do eu, Freud (1921/1973) descreve a identificação a um líder que agrega o grupo promovendo identificações entre seus membros, os quais substituem, via fascinação, o ideal do eu singular dos indivíduos pelo ideal coletivo. Por conta disto é preciso apontar com precisão o que significa conceber o final da análise como a queda dos ideais, pois, lido superficialmente, isto pode sugerir a coincidência equivocada entre singularidade e individualidade ou mesmo narcisismo e, desta forma, fazer coro ao discurso dito realista.

Esta questão nos alerta para dois problemas. Um é a promoção do encobrimento das ilusões contemporâneas — que remetem ao auto-engendramento, à superação da dependência simbólica ao Outro e promovem objetos-fetiches a compulsão a seu consumo, a fascinação às tecnologias e soluções científicas. As ilusões permitem a construção de um roteiro de realizações, fazendo supor ao sujeito que, no fim, o objeto estará lá, pleno, realizado. Não diz respeito ao ideal, mas à idealização, processo que envolve o engrandecimento e superestimação do objeto.

O outro problema refere-se ao modo de conceber o ideal do eu, como a fascinação e alienação a um coletivo. Diferente disto, vemos a importância deste conceito em indicar a demarcação simbólica de uma posição na relação com os outros, indicada por um traço com valor de significante. O ideal do eu, embora fundado narcisicamente e pelo desejo do Outro, traduz-se pela possibilidade de produzir e buscar objetos fálicos e lugares que tomam a forma de ideais que orientam os laços com o Outro, os laços sociais, regidos pela ética de não se deixar ser agido pelo outro, mas sim sustentado pelo desejo e pelas identifica- 
ções. Desta forma, não há supressão do laço com o outro, nem escravização a este. A estratégia do discurso totalitário está em fazer supor que estas são as alternativas do sujeito.

Dizendo melhor, a distorção promovida nos discursos totalitários potencializa e faz coincidir o ideal do eu com o objeto de gozo dando a ele uma solidez estática que fascina e, aliada ao supereu, paralisa os processos criativos e desresponsabiliza o sujeito da apreciação própria e de seu compromisso. Isso homologa o sujeito que se sacrifica a custo do sofrimento, com o perigo de se colocar como instrumento do gozo do Outro. A característica das manifestações da violência contemporânea está, justamente, em que estas comparecem em outro lugar, aparentemente desvinculadas do discurso que as embala.

Apontando a compatibilidade da Filosofia na alcova com a Crítica da razão prática, Lacan afirma que a verdade da razão prática (ou vontade) de Kant está em Sade: “...Kant, por ser questionado 'com Sade', ou seja, com Sade fazendo às vezes [...] de instrumento, confessa o que está incluído no sentido do 'Que quer ele?’”. Situa a vontade de Kant como vontade de gozo, explicando "que se trata do sujeito reconstituído da alienação, ao preço de ser apenas o instrumento do gozo” (LACAN, 1963/1998, p.786).

Fundamentado em uma dimensão ética que marcou a história da filosofia, Kant formula os imperativos categóricos e revela sua verdade; mas essa verdade só se elucida quando Sade aponta o limite de seu ensino. Ao falar sobre sofrimento, Sade coloca o sujeito como instrumento do gozo do Outro. Freud, quando formula o conceito de supereu, já percebera, ao citar Kant, a sua relação com os imperativos morais. Mas Lacan revela o ponto que transforma o sujeito da moral, tal qual formulada por Kant, em instrumento do gozo:

\footnotetext{
"Essa relação, parece-me, também, suficientemente ressaltada no terceiro capítulo que concerne aos móveis da razão pura prática. Com efeito, Kant admite, contudo, um correlato sentimental da lei moral em sua pureza, e... não é outra coisa senão a própria dor... Em suma, Kant tem a mesma opinião de Sade...” (LACAN, 1960/ 1991, p.102)
}

Podemos, então, verificar que o discurso contemporâneo supõe um sujeito que aparenta uma relação sem embaraço com seu objeto, sem pathos, como diria Kant, e tematiza para a psicanálise uma problemática que diz respeito aos impasses do sujeito com seu objeto de gozo. Esse tema abre algumas questões: o sujeito da psicanálise, evanescente e singular, não é um sujeito abstrato, mas sim um sujeito atravessado pelo gozo e pelo desejo. Esse desejo é singular, mas não individual. É remetido ao desejo do Outro, regulado por um discurso: o discurso do Outro, que o posiciona no laço social. 
Os termos aqui trabalhados se reapresentam: gozo, lei, anonimato, dívida e sacrifício. O gozo de um objeto que recalca a submissão ao Outro e permite um acesso privilegiado a si supõe um modo de impugnar a exigência do Outro e da Cultura, sem renúncias. Assim, não há dívida simbólica. Não reconhecer a dívida simbólica significa não reconhecer a castração. Daí a idéia enganosa de acesso ao gozo. No entanto, o desejo diz respeito à articulação própria que nos enraíza em uma história particular, o que exige que a dívida seja paga. Todavia, se ao desejo se paga com o gozo, com “uma libra de carne” (LACAN, 1963/1998, p.386), como se paga o gozo? Qual é o valor estipulado?

O ideal acena, o fantasma encena. O sujeito visa e encontra no Outro as próprias cenas e experiências de satisfação, reatualizando seu gozo na repetição. Mas o encontro pleno não chega, apesar do sacrifício e da submissão às leis da sociedade. Há um erro, uma culpa ou desculpa para o Deus-pai que sabe sobre o seu bem, mas não o deixa alcançar, que abandona e decepciona, restando o ressentimento e a amargura. O sujeito então se volta para as promessas de gozo, para a realidade oferecida pelo discurso do outro.

Nesse sentido, a psicanálise aposta em um mais-além das ilusões, em um trabalho de remissão do sujeito à verdade de seu desejo que o remete a uma historicização de seu desejo, à constatação de sua fantasia fundamental e à conseqüente abertura para a criação de novos sentidos da existência. A prática da psicanálise, que reconhece no desejo a verdade do sujeito exigindo a demonstração daquilo que o recalca (LACAN, 1960/1991, p.102), causa impacto no contexto da economia do gozo que fundamenta as atuais correntes discursivas. Assim, pensar as especificidades desta economia do gozo no atual contexto discursivo transforma-se em questão para a prática psicanalítica, por exemplo, na abordagem da toxicomania como emblemática dos impasses do sujeito contemporâneo (ROSA, 2005).

São essas as questões recalcadas nas modalidades de laço social ensejadas pelo discurso capitalista, as quais empurram violentamente o sujeito ao gozo, sob a forma de consumo e lucro desmedido ou de sofrimento e geram, para além do mal-estar, violências. Esta estratégia concebe sujeitos alheios, descomprometidos frente a uma realidade posta (imposta), em que são suspensos seus dilemas éticos, recolocados pela psicanálise. Diz Lacan em A ciência e a verdade: "Por nossa posição de sujeito sempre somos responsáveis. Que chamem a isto como quiserem, terrorismo” (LACAN, 1966/1998, p.873). A psicanálise comparece, através do sujeito do inconsciente, como modo de resistência a instrumentalização social do gozo.

A psicanálise, em vez de adaptação à realidade, enfatiza o encontro com o real pulsional, traumático, pois constata que o objeto do desejo não existe na realidade. Não há um sentido estabelecido para a vida. Só vazio. Não há como responder 
ao che vuoi? (o que o outro quer?). O sujeito ofuscado pela imagem de si estremece no encontro com o real pois se depara com a sua condição trágica. No desejo está a verdade do sujeito.

Mas o sujeito é um vazio sem autor e seu desejo é uma falta-a-ser. É preciso haver um ato de assentimento ao nada e a instauração de um lugar vazio, quando então a morte passa a sustentar a vida. Só a certeza do fim possibilita suportar esta história. O lugar vazio no Outro não enuncia a lei. Cabe, pois, ao sujeito, enunciá-la e tomá-la como esteio que determina o lugar do gozo. Desse modo, “cada um, cada uma, é responsável por seu inconsciente e pela Lei que nele se articula... É esse o móbil de nossa interrogação sobre a Lei: de fato, longe de ser uma simples negação privativa, ela deve ser uma borda que sirva de apoio" (JULIEN, 1996, p.94). Julien avança no tema, apontando que o próximo fica clivado entre o que pode ser rastreado até uma informação proveniente do corpo, que reconhecemos à nossa imagem, e a Coisa, o desconhecido, o irrepresentável. Toca-se aí o lugar do perigo, da maldade, da loucura, da perda do sentido.

Ao ultrapassar o limite de seu sentido, o homem pode fazer a experiência do seu desejo: tocar o real com o significante. Só lhe resta criar, o gozo criador que não visa preencher um vazio impossível, mas dar contorno, dar bordas ao que não tem bordas, mantendo o enigma (JULIEN, 1996, p.111). Entendemos que "elevar o objeto à dignidade da coisa”, modo como Lacan (1960/1991, p.140) aborda a problemática da sublimação, é esvaziá-lo do sentido prévio, de sua condição de objeto do desejo, para colocá-lo a serviço do sujeito que pode inventar o que fazer dele, com ele, sendo aqui o objeto causa de desejo.

“Agiste conforme o seu desejo?" (LACAN, 1960/1991, p.372) é questão que se opõe à ética tradicional construída sobre a Moral. Destacamos que está aí uma dimensão de ato e não apenas de uma intenção. A ética é ato que dá um destino ao excesso. Se o ato for ético — só se saberá a posteriori —, é risco, pois convoca desejo e gozo e faz marca no Outro, inscrição histórica de um desejo. Com essa inscrição, mudam-se as coordenadas simbólicas e imaginárias, rompe-se o continuum da história ao suspender a estrutura simbólica que dá sentido ao ato, para garantir que ela não se reduza a um tempo morto e sem acontecimentos. Toca os registros chamados por Lacan de RSI — o real, simbólico e imaginário. O ato, que seja em palavra, não é inocente, é sempre comprometido, um compromisso que deixa sua marca inscrita na cultura. Ato político porque é modo de resistência à instrumentalização social do gozo. 


\section{REFERÊNCIĀS}

FREUD, S. (1972) Edição standard brasileira das obras completas de S. Freud. Rio de Janeiro: Imago.

(1900) “A interpretação dos sonhos”, v.IV, p.1-664.

(1921) “A psicologia das massas e a análise do eu”, v.XVIII, p.91-185.

(1927) "O futuro de uma ilusão”, v.XXI, p.15-71.

GRAZIANO, F. (2005) "Escola da ilusão perdida” (editorial). Folha de S.Paulo, 23 de janeiro, p.3.

JULIEN, P. (1996) O estranho gozo do próximo: Ética e psicanálise. Rio de Janeiro: Jorge Zahar.

LACAN, J. (1960/1991) O Seminário livro 7, A ética da psicanálise. Rio de Janeiro: Jorge Zahar.

_. (1963/1998) “Kant com Sade”, in Escritos. Rio de Janeiro: Jorge Zahar.

(1964/1979) O Seminário livro 11, Os quatro conceitos fundamentais da psicanálise. Rio de Janeiro: Jorge Zahar.

. (1966/1998) “A ciência e a verdade”, in Escritos. Rio de Janeiro: Jorge Zahar.

. (1969-1970/1992). O Seminário livro 17, O avesso da psicanálise. Rio de Janeiro: Jorge Zahar.

. (1974/1993) Televisão. Rio de Janeiro: Jorge Zahar.

QUINET, A. (1999) A ciência psiquiátrica nos discursos da contemporaneidade. Disponível em: www.estadosgerais.org (Estados Gerais da Psicanálise).

ROSA, M. D. (2004). "A psicanálise e as instituições: um enlace éticopolítico”. Trabalho apresentado no V Colóquio A Psicanálise, as Instituições e a Infância, do Lepsi do Instituto de Psicologia e Faculdade de Educação da USP, em outubro de 2004. Disponível em: www.fe.USP.br/ lepsi (Biblioteca Eletrônica da Scielo).

. (2005a). "Gozo e política na psicanálise: a toxicomania como emblemática dos impasses do sujeito contemporâneo”, in Trauma e psicanálise. São Paulo: Pulsional (prelo).

. (2005b). "Do terror paralisante ao convite à criação conjunta". Trabalho apresentado na oficina Viver e Morrer nas Grandes Cidades. A rua e seus avessos: a experiência de um diálogo de imagens entre duas cidades; Atividade proposta pelo PPG Psicologia Social e Institucional / Instituto de Psicologia UFRGS, no Fórum Social Mundial.

SAFATLE, V. (2002): “A política do real de Slavoj Zizek” (Pósfácio), in Bemvindo ao deserto do real (ZIZEK, 2002). São Paulo: Boitempo.

ZIZEK, S. (1991). O mais sublime dos histéricos. Rio de Janeiro: Zahar. (1996). "Como Marx inventou o sintoma", in Um mapa da ideologia. Rio de Janeiro: Contraponto. 
Miriam Debieux Rosa

debieux@terra.com.br

Taeco Toma Carignato

taecotoma@hotmail.com

Sandra Letícia Berta

bertas@uol.com.br 